Redjem Hadef, Klaus Peter Geigle, Jochen Zerbs, Robert A. Sawchuk, David R. Snelling, The concept of 2D gated imaging for particle sizing in a laminar diffusion flame, Appl. Phys. B 112 (2013) 395-408.

The original publication is available at www.springerlink.com

http://dx.doi.org/10.1007/s00340-013-5507-1 


\title{
The concept of 2D gated imaging for particle sizing in a laminar diffusion flame
}

\author{
Redjem Hadef ${ }^{1}$, Klaus Peter Geigle ${ }^{2 *}$, Jochen Zerbs ${ }^{2}$, Robert A. Sawchuk ${ }^{3}$, David R. Snelling ${ }^{3}$ \\ ${ }^{1}$ Université Larbi Ben M'Hidi, Institut de Génie Mécanique \\ 04000 Oum El Bouaghi, Algerie \\ ${ }^{2}$ German Aerospace Center (DLR), Institute of Combustion Technology \\ Pfaffenwaldring 38-40, 70569 Stuttgart, Germany \\ ${ }^{3}$ National Research Council of Canada (NRC), Measurement Science and Standards \\ 1200 Montreal Road, Ottawa, ON, K1A 0R6, Canada \\ *E-mail: klauspeter.geigle@dlr.de \\ Phone: ++49-711-6862-398 \\ FAX: ++49-711-6862-578
}

\section{Keywords Soot, Diffusion Flame, Laser-Induced Incandescence}

\begin{abstract}
In this work time-resolved laser-induced incandescence (TiRe LII) has been employed to measure primary particle diameters of soot in an atmospheric laminar ethylene diffusion flame. The generated data set complements existing data determined in one single location and takes advantage of the good spatial resolution of the ICCD detection. Time resolution is achieved by shifting the camera gate along the LII decay. One key input parameter for the analysis of time-resolved LII is the local flame temperature. This was determined on a grid throughout the flame by coherent anti-Stokes Raman scattering. The accurate temperature data, in combination with other published data from this flame, are well suited for soot model validation purposes while we showed feasibility of a shifted gate approach to deduce 2D particle sizes in the chosen standard flame.
\end{abstract}




\section{Nomenclature}

\section{Terms}

$\dot{Q}_{\text {int }} \quad=\rho c \frac{\pi D^{3}}{6} \frac{d T_{P}}{d t} \quad$ change of internal energy of the soot particle

$\dot{Q}_{\mathrm{abs}} \quad=\alpha_{\lambda, l a s} \frac{\pi D^{2}}{4} q(t) \quad$ rate of energy absorption from the laser pulse

$\alpha_{\lambda, \text { las }}=\frac{4 \pi D}{\lambda_{\text {las }}} E(m) \quad$ absorption efficiency of soot

$\dot{Q}_{\text {sub }} \quad=-\frac{\Delta H_{v}}{M_{v}} \frac{d m}{d t} \quad$ rate of heat loss by soot surface sublimation

$\dot{Q}_{\text {cond }}=h_{\text {cond }} \pi D^{2}\left(T_{p}-T_{g}\right) \quad$ heat conduction to ambient gaseous species due to collisions

$\dot{Q}_{\mathrm{rad}} \quad=\pi D^{2} \int_{0}^{\infty} \varepsilon_{\lambda} M_{\lambda}^{0} d \lambda \quad$ blackbody-like LII radiation

\section{Variables}

$c \quad$ soot heat capacity

$C_{\text {opt }}$ optical function (detection system response)

$D_{0} \quad$ Primary particle diameter without laser excitation, $\mathrm{m}$

CMD Count median diameter of log-normal distribution of primary particle diameters, $\mathrm{m}$

$D \quad$ Particle diameter, $\mathrm{m}$

$E(m)=0.232+1.2546 \cdot 10^{+5} \lambda \quad$ Refractive index function

F Laser fluence $\mathrm{W} / \mathrm{m}^{2}$

$f_{v} \quad$ Soot volume fraction, ppm

$h_{\text {cond }}$ Heat transfer coefficient, containing thermal accommodation coefficient $\alpha_{\mathrm{T}}, \mathrm{W} \cdot \mathrm{m}^{-2}$

$M^{0} \quad$ Blackbody spectral radiation, $\mathrm{W} \cdot \mathrm{m}^{-2} \cdot \mathrm{m}^{-1}$

$M_{v} \quad$ Molar mass of soot vapor, $\mathrm{kg} \mathrm{mol}^{-1}$

$m$ Particle mass, $\mathrm{kg}$

$N_{p} \quad$ Number density of the soot particles, $\mathrm{m}^{-3}$

$q(t)$ Temporal laser intensity profile, $\mathrm{W} \mathrm{m}^{-2}$

$R \quad$ Particle radius, $\mathrm{m}$

$S_{\text {LII }} \quad$ LII signal

$T_{p} \quad$ Particle temperature, $\mathrm{K}$

$T_{g} \quad$ Gas temperature, $\mathrm{K}$

$t \quad$ Time, $\mathbf{s}$

$U$ Velocity, $\mathrm{m} / \mathrm{s}$

$V \quad$ Probe volume, $\mathrm{m}^{3}$

\section{Greek symbols}

$\alpha_{\mathrm{T}} \quad$ Thermal accommodation coefficient

$\beta \quad$ Mass accommodation coefficient

$\Delta H_{\mathrm{v}}$ Enthalpy of vaporization, $\mathrm{J} \mathrm{mol}^{-1}$

$\varepsilon \quad$ Emissivity of soot, containing $E(m)$ 
$\lambda \quad$ Wavelength, $m$

$\begin{array}{ll}\rho & \text { Density, } \mathrm{kg} \mathrm{m}^{-3} \text { (soot or ambient gas) } \\ \sigma_{\mathrm{g}} & \text { Geometric width of a log-normal distribution }\end{array}$

\begin{tabular}{ll}
\multicolumn{2}{l}{ Subscripts } \\
abs & Absorption \\
cond & Conduction \\
det & Detection \\
sub & Sublimation \\
exc & Excitation \\
$\mathrm{g}$ & Gas \\
int & Internal \\
las & Laser \\
rad & Radiation \\
v & Vapor
\end{tabular}

\section{Introduction}

Soot particles formed during combustion processes significantly affect the performance and durability of many engineering systems such as gas turbines and diesel engines. Soot emissions from various sources have also been reported to have serious adverse effects on human health because these nanometre size particles are believed to be responsible for increasing the risk of death by as much as $15 \%$ in cities with heavy air pollution [1]. Moreover, it has recently been argued that flame generated soot might be a major contributor to global warming either directly or by serving to contrail formation [2-5]. These important technological and environmental implications motivate advanced theoretical research for a complete understanding of the factors governing soot formation in flames. For this purpose, the parameters of interest required to validate kinetic models for the prediction of this complex process (inception, formation, oxidation,...) are soot particle size, overall soot concentration, and spatial soot distribution. In addition, accurate temperatures are an essential parameter for modeling soot formation. These quantities can not be measured easily with intrusive techniques and the present investigation seeks to address this need for high quality validation data. Different approaches have been described in literature that are suited to determine soot properties inside flames non-intrusively.

One approach is the simultaneous application of Rayleigh scattering, 2D laser-induced incandescence and laser extinction (RAYLIX) [6-8] providing particle sizes and numbers as well as soot concentrations. Here, particle size is derived ratioing scatter and LII signal that show different dependencies on particle size, i.e. $r^{6}$ and $r^{3}$, respectively. This tool has been used to characterize laminar diffusion flames fuelled by acetylene and various turbulent flames so far. Although a quite elegant diagnostics, the precision of 
the finally resulting parameters soot volume fraction, particle size and number depend on the accuracy of both techniques involved. As LII imaging (the often claimed "LII plateau" is not really a plateau, for example [7,9]) and scattering have a different response to the local laser fluence, variations along the laser sheet can influence the precision while a correction of this effect is not easily possible. This can become crucial for strongly sooting flames with significant laser attenuation. Besides this systematic issue of mapping images received from different techniques, the accuracy of $r$, as detailed in [7], depends on the precision of $f_{v}$, introducing several well known uncertainties of LII calibration [10]. For the scattering portion of the diagnostics suite, the effect of aggregation is neglected [7]. However, TEM images clearly indicate the presence of aggregates in this type of flame [11] while the influence of aggregation on scattering is non-negligible, necessitating an independent validation of this valuable combination of diagnostics.

A different approach to determine particle sizes uses the LII decay time. Will [12] used two distinct camera gates to make use of the different cooling behavior of large versus small primary particles to deduce the primary particle size without needing calibration. Here, the authors neglected the effect of aggregation in analyzing the signal ratio for both chosen delay times. Although this assumption is not entirely justified, deviations for in-flame soot exist but are not essential, as recent research demonstrated [13]. Will et al. [12,14] presented the feasibility of the technique and showed its application to $\mathrm{C}_{2} \mathrm{H}_{4}$ laminar diffusion flame; a description of the optimization of the experimental parameters and a detailed uncertainty discussion are also contained in this paper. As described there, one parameter essentially influencing the precision of particle sizes determined by this approach is the knowledge of local gas temperature, in addition very important to soot modelling. In [15] the authors report a full 2D map of particle sizes in this flame, indicating particle sizes between 20 and $80 \mathrm{~nm}$ and remarking this to be significantly larger than in similar flames [16]. One potential source of error is the missing knowledge of the exact flame temperatures. Later studies employing $0 \mathrm{D} T \mathrm{TiRe}$ LII (photomultiplier detection) and TEM reported primary particle diameters around $30 \mathrm{~nm}$ in the most homogeneous part of the laminar diffusion flame (known as Gülder flame [11,17,18]). This flame position, $\mathrm{HAB}=42 \mathrm{~mm}$ on the flame center line was later defined as standard position for basic LII studies during the first international workshop on LII [19]. The study described in [11] is limited to this very homogeneous part of the flame, where spatial resolution is uncritical and a large measurement volume generates high LII signal levels that serve for very accurate data analysis. Using a streak camera for one dimensional time resolved measurements combines a higher dimensionality of the detection with an excellent temporal resolution [20] well suited for one- dimensional flames.

The mentioned importance of exact flame temperatures for determination of particle sizes by LII has been discussed by Schraml et al. [21] who deduced flame temperatures from soot emission spectra. The authors admitted that "it is obvious that a temperature measurement with this method is only possible in regions where sufficient high soot concentrations are present ...". To circumvent this severe limitation we chose coherent anti-Stokes Raman scattering to measure temperatures. 
Beyond above cited references describing flames, there still is a need for comprehensive data sets for soot modelling. In this paper we present accurate flame temperatures that, in combination with other published data from this flame, are well suited for soot model validation purposes. Concerning optical diagnostics, particle sizing in flames by LII is rarely validated, in contrast to cold or post flame soot [22], thus demands for comparison with different other diagnostic approaches, preferably laser-based ones. Therefore, we prove feasibility of a shifted gate TiRe LII approach resulting in a 2D image of primary particle sizes for one of the three simple flames identified as LII standard flames [19], i.e. the $\mathrm{C}_{2} \mathrm{H}_{4}$ laminar diffusion flame. Time resolved LII is employed to deduce primary particle size distributions in the so called Gülder flame, while data analysis is based on highly precise CARS temperatures minimizing one of the main error sources of TiRe LII.

\section{Laser-induced incandescence model}

\subsection{LII model implementation}

The technique of LII involves heating particles up to typically around $4000 \mathrm{~K}$ with a high-power pulsed laser of several nanoseconds duration followed by cooling down until they reach thermal equilibrium with the combustion environment. A more detailed description of our implementation of the LII process is published in [23] while a more general overview is provided in the following. The theoretical model of the LII process is described by energy and mass balances between a single spherical primary soot particle of mass $m$ and diameter $D$ and its surrounding at a temperature $T_{g}$ (Fig. 1):

$\dot{Q}_{\text {int }}=\dot{Q}_{\text {abs }}-\dot{Q}_{\text {sub }}-\dot{Q}_{\text {cond }}-\dot{Q}_{\text {rad }}$

and

$\frac{d m}{d t}=\frac{d}{d t}\left(\rho \frac{\pi D^{3}}{6}\right)=-\pi D^{2} \rho_{v} U_{v}$

The different terms of Eq. 1 denote the change of internal energy of the soot particle, the rate of energy absorption from the laser pulse, the rate of heat loss by surface sublimation, heat conduction to ambient gaseous species due to collisions and the blackbody-like LII radiation, respectively.

In our implementation, differing from others in details, we use temperature dependent particle density $\rho$ and heat capacity $c[24,25]$ for the internal energy, a wavelength dependent $E(m)$ for absorption and emission [26,27] in the Rayleigh regime, i.e. primary particles are significantly smaller than the used wavelengths. Conduction at the given conditions (ambient pressure, flame temperatures) is considered to be governed by free-molecular flow [28] and a thermal accommodation coefficient of $\alpha_{\mathrm{T}}=0.3$ is used [29]. Sublimation is assumed to be kinetically controlled with a mass accomodation coefficient $\beta=0.5$ for $C_{1}$ and $C_{2}$, significantly smaller values for the other $C_{n}$ clusters (including $C_{3}$ to $\mathrm{C}_{7}$ ) [25], temperature-dependent enthalpy of formation $\Delta H_{n}$, molecular weight $M_{n}$ and vapor pressures $p_{n}$.for the included $C_{n}$ species ( $n=1$ to 7 ). 
Using a time step of 5 ps, Eqs. 1 and 2 are solved numerically using the fourth-order Runge-Kutta method to derive the particle temperature and size as a function of time during and after the laser pulse. The results of this integration are used to calculate the temporal laser-induced incandescence radiation collected at a given wavelength $\lambda_{\text {det }}$ (apart from a calibration constant for the optical system) with the help of Planck's radiation function as:

$$
S_{L I I}(t)=C \frac{E(m)}{\lambda_{\operatorname{det}}^{6}}\left[\frac{D(t)^{3}}{\exp \left(h c / \lambda_{\operatorname{det}} k_{B} T\right)-1}-\frac{D_{0}^{3}}{\exp \left(h c / \lambda_{\operatorname{det}} k_{B} T_{g}\right)-1}\right]
$$

Where $C$ is a constant parameter and $E(m)$ is a wavelength dependent function of the soot refractive index $\mathrm{m}$. Melton [30] demonstrated that Eq. 5 indicates that the spectral intensity LII signal is proportional to the particle volume, and its peak, taken within a certain range of laser fluences, has been shown to be proportional to soot volume fraction. Thus and by means of calibration, the LII technique becomes a powerful diagnostic tool for spatially and temporally resolved measurement of soot volume fraction in a wide range of applications, such as laminar and turbulent flames, in-cylinder combustion, and engine exhaust gas characterization.

Besides measuring particle concentration, time-resolved LII has been explored as a potentially powerful tool for characterizing the primary particle diameter (mean or distribution) in various combustion systems. Its principle is based on the fact that conduction heat loss from the particles to the surrounding gas is the dominant particle cooling mechanism after the laser pulse. According to the model, the different energy loss contributions provide cooling at different rates. Fig. 1 shows the effects for our approximately used fluence. Thus, the temporal signal emission profile is a function of initial size and temperature, the surrounding gas temperature and the overall cooling rate. The overall particle cooling rate, characterized by the temporal decay rate of the LII signal can be related to the particle size since larger particles cool slower than small ones due to a smaller surface area-to-volume ratio (Fig. 2). For determining initial particle sizes either $D$ must be considered variable when using high fluence and the full temporal profile or can be assumed constant for low fluence.

The effect of soot aggregation has been neglected, thus no shielding factor was used. Aggregation changes during soot formation, thus within the very same flame [31]. Because detailed and spatially resolved information on aggregation is (to our knowledge) not known for the flame under study, we chose to neglect aggregation for the current feasibility test.

\subsection{LII model validation}

It is well known that the accuracy of theoretical LII models, in particular the heat conduction sub-model and the uncertainty in values of many unknown optical and thermodynamic parameters, has significant and direct impact on the accuracy of primary particle sizes determined from LII measurements. For this 
reason, validation of our present model is desirable and consequently has been conducted with experimental single wavelength decay curves [25] for particles of known primary particle diameter (35 nm, assumed monodisperse) where time-resolved LII measurements were performed over a wide range of laser fluences in a coflow $\mathrm{C}_{2} \mathrm{H}_{4}$ diffusion flame at atmospheric pressure.

Figure 3 shows the comparison of our model results for these normalized experimental data for various values of the fluence as we showed in [23] in more detail displaying qualitatively good agreement of our modeled decay behavior for a short time window of $80 \mathrm{~ns}$. The transition from the low fluence regime to the high fluence regime, characterized by significantly faster decay due to surface vaporization is well represented. Concerning the short-time behavior we had demonstrated even good qualitative agreements with experiments for low to intermediate fluences (up to $0.2 \mathrm{~J} / \mathrm{cm} 2$ ). For increasing fluences, the onset of soot sublimation leads to increasing deviations initially only influencing the agreement in the first few nanoseconds, and for high fluence the whole decay curves [23]. This is mainly due to difficulties in well describing the sublimation sub-model of LII, frequently occurring in LII modeling. For the fluence range used in our experiments, the agreement is well acceptable. This statement is specifically valid for our current experiments, where the use of a discrete camera gate (rather than a photomultiplier decay curve as in [23]) prevents high temporal resolution. Therefore, Fig. 3 rather visualizes the performance of our model for longer delay times, similar to the time range used for our presented shifted-gate approach. To conclude, the used model demonstrates qualitatively acceptable agreement with the validation data from [25] and thus can be used as a valuable tool for analyzing LII decay curves recorded by shifting the ICCD gate.

\subsection{Size distributions}

Equation 5 applies to monodisperse particle ensembles (uniform size $D_{0}$ ). It is well known that soot particles in flames are polydisperse and have a certain size distribution. This has a significant impact on the LII signal as the cooling of the laser-heated particles strongly depends on the particle size; consequently the measured radiation is the cumulative signal from particles of various sizes. For an invariant energy density within the laser sheet, an integration considering the particle-size distribution function $P D F(D)$ yields the total LII signal $J(t)$ at the detector surface:

$$
J(t)=C_{o p t} N_{p} \cdot V_{m} \int_{0}^{\infty} P D F(D) . S_{L I I}(t) . d D
$$

with the optical function $C_{o p t}$ describing the detection system response.

It is assumed that the particle number concentration $N_{p}$ is constant in the probe volume $V_{m}$ during a single LII event.

Although size distributions have occasionally been found to be bi-modal, TiRe LII is insensitive to the smaller mode due to its typically negligible total volume relative to that of the larger mode [32]. For the 
LII-relevant mode, a widely accepted assumption is that for hydrocarbon flames the size distribution follows a log-normal shape [33]:

$$
P D F(D)=\frac{1}{\sqrt{2 \pi} D \ln \sigma_{g}} \exp \left[-\left(\frac{\ln D-\ln C M D}{\sqrt{2} \ln \sigma_{g}}\right)^{2}\right]
$$

The distribution is described by the count median particle diameter CMD and the geometric standard deviation $\sigma_{g}$ to be used as relevant fit parameters. The agreement between model and experiment is expressed by the maximum likelihood estimator:

$$
\chi^{2}=\sum_{i=1}^{N}\left(\frac{y\left(t_{i}\right)-y\left(t_{i}, C M D, \sigma_{g}\right)}{\sigma_{\exp }}\right)^{2}
$$

Where $y_{i}$ is the measured quantity, $y\left(t_{i}, C M D, \sigma_{g}\right)$ is the model prediction for the fit parameters $C M D, \sigma_{g}$, $N$ is the number of experimental data points and $\sigma_{\text {exp }}$. is the experimental standard deviation that can be either taken from the experimental input files or simply set to one. $i$ represents the time steps of experiment and accordingly calculation, based on the temporal resolution of the decay curves.

The vaporization threshold of soot for $1064 \mathrm{~nm}$ excitation is reported to be between 0.1 and $0.5 \mathrm{~J} / \mathrm{cm}^{2}$ $[34,17]$. Our chosen average fluence of $0.4 \mathrm{~J} / \mathrm{cm}^{2}$ is in the low vaporization regime shortly above or close to the LII threshold and clearly below high laser fluence of $0.7 \mathrm{~J} / \mathrm{cm}^{2}$ as defined in [25] or [19]. Thus all particles should reach similar peak temperatures, neglecting the wings of the Gaussian profile in horizontal dimension, where only small portions of signal are generated. Our curve fitting allows for variation of the contribution of sublimation. Moreover, we tested the influence of minor modification of some parameters on the curve fit quality. These are $\beta$ for the sublimation term, $\alpha_{T}$ for cooling and $E(m)$ which, for fixed laser fluence, determines the peak temperature. As quality criteria the minimum value of $\chi^{2}$ was used. Variation did not lead to the need of significantly different values of the not directly measurable parameters $\beta$ and $\alpha_{\top}$ relative to those used in [23] to fulfill $\chi^{2}$ minimization.

\section{Experiment}

\subsection{Burner}

In this experiment an atmospheric-pressure, axisymetric-coflow laminar ethylene/air diffusion flame is employed. It has been suggested as standard flame for LII research for the first international workshop on LII [19], thus collected data can serve to validate new diagnostics combinations and to validate soot models [35,36]. The burner stabilizing the flame consists of a 10.9-mm-inner-diameter fuel tube, centered in a 100-mm-diameter air nozzle. The air passes through packed beds of glass beads and porous metal disks to achieve uniform flow, suppress flow disturbances and prevent flame instabilities. The fuel-flow rate is $0.194 \mathrm{slm}$ and that of the outer air is $284 \mathrm{slm}$. Both flow rates are controlled using 
mass flow controllers. These conditions result in a visible flame height of about $65 \mathrm{~mm}$ (Fig. 4).

\subsection{LII setup}

The LII signal was excited by a Nd:YAG laser (Spectra Physics GCR 290), with a repetition rate of $10 \mathrm{~Hz}$ and pulse duration of 7-9 ns (FWHM). The $1064 \mathrm{~nm}$ output is preferred because it does not excite undesirable laser-induced fluorescence (LIF) from species such as polycyclic aromatic hydrocarbons associated with soot formation. In order to obtain a sufficiently stong and long enough lasting LII signal, our experiments are performed at a spatially averaged laser fluence of $\sim 0.4 \mathrm{~J} / \mathrm{cm}^{2}$.

A light sheet is formed with a height of approximately $40 \mathrm{~mm}$ and a waist thickness of about $300 \mu \mathrm{m}$ by a suitable pair of cylindrical negative (focal length $f=-80 \mathrm{~mm}$ ) and spherical positive $(f=1000 \mathrm{~mm}$ ) lenses providing a long focus. For a better definition of the light sheet, a rectangular aperture was employed behind the second lens. The resulting intensity variation was $\pm 15 \%$ along the vertical dimension of the sheet while the horizontal profile is assumed to be Gaussian. The induced incandescence emitted perpendicular to the incident sheet was imaged onto an intensified charge coupled device (ICCD, PCO Dicam Pro dual frame) camera. A narrow band interference filter with transmitting wavelength range of $445-470 \mathrm{~nm}$ was placed in front of the camera to prevent detection of laser light scattering from soot particles and to reject most background luminosity. An illustration of the experimental layout is shown in Fig. 5.

During the first gate of $20 \mathrm{~ns}$ duration immediately before the laser pulse, the flame luminosity background is detected. The second gate of equal duration was shifted from starting with the laser pulse to delayed by up to $1.4 \mu$ s and is used for detection of the signal. One hundred LII images were acquired for each instant during this sequential measurement; these were subsequently corrected for flame luminosity and for inhomogeneities of the ICCD chip sensitivity. Data reduction included a slight tilt to correct for camera mounting issues and symmetrization by averaging data of both halves of the flame. The concept of 2D particle sizing was first shown as prove of concept using only two distinct camera gates during the decay curve $[12,14,15]$. Fig. 6 shows a typical two-dimensional LII image of the studied flame (right) and the respective soot luminosity (left). Quantification of the initially relative LII image into soot concentrations was accomplished using the peak value from [37].

\subsection{CARS implementation}

The CARS temperatures (see Fig. 7), which are used for TiRe LII analysis are an extension of those data published in [38] and [39] and have already been used for model validation in [35]. The CARS system, which has been described in [40], used a single mode $532 \mathrm{~nm} \mathrm{Nd:YAG} \mathrm{pump} \mathrm{laser} \mathrm{and} \mathrm{a}$ modeless $(607 \mathrm{~nm})$ dye laser [41]. The resulting CARS spectrum at approx. $473 \mathrm{~nm}$, detected by a spectrometer equipped with an intensified linear array detector, contains the temperature information 
in the resolved rovibrational intensity distribution of monitored $\mathrm{N}_{2}$ molecules. The use of this CARS system in a methane air flame using the same burner has been described previously [41].

The experimental spectra are fitted to a library of theoretical CARS spectra allowing for variations of the $\mathrm{N}_{2}$ concentration in the flame. In more heavily sooting regions of the flame laser generated $\mathrm{C}_{2}$ caused an absorption of segments of the CARS spectrum [42] that were then excluded from the fitting routine [38] in contrast to others, who shifted the CARS signal away from these $\mathrm{C}_{2}$ Swan band interferences $[43,44]$. That approach reduces the precision in these parts of the flame but still provides reliable flame temperatures [38].

The CARS system used a BOXCARS configuration and the measurement volume was a cylinder approximately $1.1 \mathrm{~mm}$ in length and $75 \mu \mathrm{m}$ in diameter. If we define the $\mathrm{x}$-axis as the long dimension of the measurement volume then the burner was scanned in the y direction so that the long dimension of the measurement volume was tangent to the radial profiles. In that way the effective radial spatial resolution varied from $0.6 \mathrm{~mm}$ at burner center to $170 \mu \mathrm{m}$ at $\mathrm{r}=1 \mathrm{~mm}$ and $40 \mu \mathrm{m}$ at $\mathrm{r}=5 \mathrm{~mm}$. CARS temperature measurements were made every $0.25 \mathrm{~mm}$ radial position from burner centre to $\mathrm{r}=8 \mathrm{~mm}$. These measurements started at a height of $2 \mathrm{~mm}$; then every $5 \mathrm{~mm}$ from 5 to $65 \mathrm{~mm}$; and then 66 and $67 \mathrm{~mm}$. These temperatures were then fitted using the 2 dimensional Mathcad LOESS fit function [45] to provide a temperature map of the burner from 2 to $67 \mathrm{~mm}$ in height and 0 to $8 \mathrm{~mm}$ radially.

For TiRe Lll-analyzed locations without explicit temperature data we performed an extrapolation using neighboured temperature information, well being aware that this might induce errors of up to $100 \mathrm{~K}$, still significantly better than estimating an ambient temperature.

\section{Results}

\subsection{Flame temperatures}

Fig. 7 shows temperature profiles for different heights in the flame. For the $55 \mathrm{~mm}$ profile, data have been smoothed using the Loess-algorithm [45] indicating the grid used for TiRe LII data analysis. Accordingly, to enable the higher resolution of the TiRe LII data grid in comparison to the CARS data, temperatures were interpolated to locations not captured by CARS. The measured temperatures peak radially off axis below $55 \mathrm{~mm}$ while the highest profile shows its peak on axis (Fig. 7). Qualitatively, this behavior is similar to the soot concentration profiles visualized in Fig. 6 and indicating the importance of temperature for soot chemistry. Low in the flame, hottest temperatures form a ridge near the stoichiometric contour. As determined by others, for example [39], temperatures peak at larger radial positions, consistent with the fact that soot is typically formed on the fuel-rich side of the stoichiometric surface, while temperatures peak close to but outside of it (see for example $[46,47]$ ). Due to the 
relatively low temperature at low heights on the flame axis, i.e. below $1500 \mathrm{~K}$, pyrolysed fuel is not yet transferred into soot. Below $20 \mathrm{~mm}$, soot is only formed in lateral regions of the flame. In these lateral positions, soot concentrations grow up to peak values of $7.5 \mathrm{ppm}$ at $\mathrm{HAB}=30 \mathrm{~mm}$. At this height, significant soot concentrations have appeared on the flame axis, induced by the sufficiently high temperatures above $\mathrm{HAB}=20 \mathrm{~mm}$ and adequate residence times under these conditions ( $\mathrm{ms}$ ). Further downstream, a relatively sharp drop in peak temperature is determined, from $2000 \mathrm{~K}$ at $20 \mathrm{~mm}$ to about $1800 \mathrm{~K}$ at $40 \mathrm{~mm}$. This behavior has equally been obtained with thermocouples [48] or using CARS spectroscopy [49] in similar flames. It is typically attributed to losses due to thermal soot radiation as suggested by the radiation loss measurements of Markstein [50]. The temperature peak broadens leading to less steep lateral gradients. Peak temperatue in the highest measured position $(67 \mathrm{~mm}$ ) is approx. $1770 \mathrm{~K}$ on the flame axis (profile not contained in Fig. 7). More detailed descriptions of temperature profiles in diffusion flames are contained for example in [48,49,51]. The major purpose in this content is their use for analysis of time-resolved LII data in a LII workshop-defined target flame. So far, ambient gas temperatures only were roughly assumed [14] while accurate, measured temperatures are the better choice.

\subsection{Particle sizing}

To determine a log-normal distribution particle size distribution from a measured LII signal in our experiment, a sequence of images as visualized in Fig. 8 is used, varying the gate delay (20 ns duration) after the laser pulse to extract a discrete temporal LII signal decay for each spatial location in the flame. To improve the signal-to-noise ratio, we binned $3 \times 3$ camera pixels, resulting in a $0.4 \times 0.4 \times 0.3 \mathrm{~mm}^{3}$ measurement volume used for data analysis on a $0.5 \mathrm{~mm}$ spaced grid. This approach is different from the conventionally used photomultipliers that provide more accurate decay traces while being limited to a OD measurement volume.

For all single positions an ensemble of LIl signals for different size distributions, thus pairs of $C M D$ and $\sigma_{g}$ was calculated for each of which the maximum likelihood estimator $\chi^{2}$ for the original signal was determined. The particle size information can then be obtained from a best-fit comparison of experimental temporal signal decay curves and those calculated (from 0 to $1400 \mathrm{~ns}$, thus including the vaporization peak).

Basing this analysis on CARS temperatures improves the accuracy of the resulting soot properties. The general uncertainty in CARS thermometry is often considered to be up to $2-3 \%$ of the absolute temperature, resulting in an error of $5 \%$ and $3 \%$ of $C M D$ and $\sigma_{g}$, respectively.

Figure 9.a shows the result in the centerline location at $42 \mathrm{~mm}$ height above burner. It should be noted that the minimum is well defined; however, it lies in a long, rather flat "valley" as discussed in [52]. This indicates that for an experimental case, with noisy signals and certain errors in experimental input 
parameters like the laser fluence, the fit might be not robust. The corresponding LII signal and particle size distribution are presented in Fig. 9.b and 9.c, respectively.

Figure 10 displays the soot primary particle diameter at various heights above the burner (HAB) and radii derived following the maximum likelihood estimator. In addition to the well characterized standard location in this flame (centreline, $42 \mathrm{~mm} \mathrm{HAB}$ ), our approach provides particle sizes for the whole flame. For the standard location defined by the 1st international LII workshop [19] our particle size of $16.5 \mathrm{~nm}$ is smaller than that determined with a $3 \mathrm{~mm}$ diameter sampling grid exposed to flame conditions for $25 \mathrm{~ms}$ and consecutive TEM image analysis [11], being 28-29 nm and in good agreement with other TEM results from similar flame locations [53]. Measurements with scattering/extinction in a similar laminar diffusion flame resulted in particle sizes of about $20 \mathrm{~nm}$ in a comparable location [54], ours and data by D'Anna et al. [54] in this position being significantly smaller than in [51] derived from scattering/extinction measurements as well.

If we allow for a different choice of the value of the thermal accommodation coefficient $\alpha_{\top}$, i.e. 0.44 from [55], instead of 0.3 for NO on graphite [29], the conduction term significantly gains importance what results in larger particle sizes in our fits. Snelling et al. [55] determined the thermal accommodation coefficient more recently for in-flame soot by fitting the soot temperature decays excited by a LII process and use of $\alpha_{T}$ as unknown or fit parameter. This choice would, in turn, lead to loss of the validation procedure chosen for our LII model implementation, thus question the validity of the particle size of the well characterized experiment chosen in [25].

Another potential source for deviations to TEM data is the fact that most LII models, as ours, assume no contact between primary particles or point contact between these when forming aggregates for calculating conduction, but typically neglecting shielding effects. Basing the heat conduction term on more realistic bridging of $10 \%$ or $25 \%$ introduces shielding effects into the conduction sub-model, thus slower temperature or signal decay of the laser-heated soot. A more detailed description on the effect of aggregation is provided in [56]. Finally, part of the discrecpancy can be attributed to the relative high fluence we used that probably is not perfectly captured by our model, in combination with the limited temporal resolution during and shortly after the laser pulse.

Despite uncertainties in part introduced by the sublimation submodel (as typical for most LII models) and neglect of other mechanisms (oxidation, melting, and annealing of the particles and nonthermal photodesorption of carbon clusters from the particle surface [25]), our 2D plot (Fig. 10) provides a good trend image of particle sizes throughout the whole flame. Regions of large particles correlate well to those exhibiting high soot concentrations (see Fig. 11 for an exemplary HAB of $30 \mathrm{~mm}$ ), as identified by Santoro and Semerjian [51], with both, $f_{v}$ and $C M D$ peaking at lower $r$ compared to the temperature. The derived width of the particle size distribution $\sigma_{g}$ follows the particle diameter (Fig. 11, right). The 
soot formation region low in the flame as well as the oxidation zone close to the flame tip are described by small particles. It should be noted, that the CCD dynamics of 12 bit leads to a limited precision for those regions of the flame that are exhibiting weak signal. In those cases, signal levels become insignificant after some hundreds nanoseconds; nevertheless, this is sufficient to deduce physically reasonable particles sizes as visualized in Fig. 10. Below a HAB of $55 \mathrm{~mm}$, profiles are characterized by a minimum in the inner part of the flame and a annular peak of particle size. The maximum value of $C M D$ is found in the annular region and is about $50-60 \mathrm{~nm}$. Compared to [15] who evaluated the signal ratio of two delay instants only, and used the continuous regime for conductive cooling, we find significantly smaller particle sizes. While the smallest particles in [15] are already clearly larger than $20 \mathrm{~nm}$, our smallest particle sizes are close to $10 \mathrm{~nm}$ low in the flame wings and at the flame tip. However, general trends in particle size are very similar to those of $[12,14,15]$. The smallest particle sizes identified and shown in Fig. 10 are most probably due to low signal levels. As evident from comparing the 2D plot (left) of LII intensity and the deduced particle sizes, the locations of $10 \mathrm{~nm}$ particles are identical with very low intensity levels. LII intensity is proportional to the third power of particle diameter (total soot volume in the measurement volume), thus resolving the particle sizes towards the flame edges is mainly prevented due to sensitivity issues of the detection system. Moreover, we analyzed equidistant locations in the flame and identifying the smallest particle size at the edges of the soot distribution that could be deduced with the present approach was not the target of the study.

One clear advantage of our approach over sampling techniques is the high spatial resolution that is defined by the sheet thickness and the camera's pixel resolution, even in combination with the chosen binning to improve signal quality. This is especially valuable for flames exhibiting steep gradients as our measurement object. The other advantage is the imaging capacity easily allowing for spatial correlations, specifically in contrast to the conventionally used detectors for point LII measurements, i.e. photomultipliers. This gain in the spatial dimension is at cost of the temporal dimension where resolution is limited, however sufficient to deduce quantitative primary particle sizes. Nevertheless, comparison to point LII measurements performed in different locations in the flame will provide additional insight. While the absolute size information will be improved in future experiments using lower laser fluence, with the weaker signal being compensated by higher camera gain, the qualitative trends and the order of magnitude provide a good validation test case for kinetic modelling in this flame.

Critical to particle sizing by LII in general is the lack of validation with independent diagnostics providing reliable size. This is specifically valid having in mind that existing diagnostics are based on different physical principles, thus the determined quantity can slightly differ, and for different type of soot (nascent soot, mature in-flame soot, post-flame soot, fuel dependency), a variety of independently derived values is to be expected (for comparison to other diagnostics see for example [57-59]). On the 
other hand, current LII models are far from providing unique results as different model parameters are chosen and validation is mostly based on different test cases [60], and agreement which model is expected to deduce the best particle sizes from an experimental LII decay curve is not yet reached. So, our set of particle sizes provides one, not necessarily the only, analysis of the acquired decay traces.

2D TiRe LII particle sizing by gate-shifting should be valuable for applications in technical systems (engines, gas turbines) where spatial correlations are important. Under these conditions, OD particle size measurements are less valuable, and existing multi-CCD systems can already provide up to 8 time-shifted frames [61]. However, due to the instationary behavior of those processes, CARS won't be available as source of instantaneous accurate temperatures as is possible for laminar flames. Another source of uncertainty inherent to $2 \mathrm{D}$ imaging with LII is the fact that physical and optical properties of soot cannot be expected to be equal in the entire flame (see for example [31] or [62] for a similar flame of different fuel). However, because detailed and spatially resolved information on optical soot properties is typically not available, the choice of commonly used values from literature, thus neglecting dependencies from location in the flame is best representing future applications of the approach.

\section{Summary}

The presented approach uses a shifted camera gate to determine two-dimensional LII decay curves. This proved feasible in determining 2D primary particle sizes in a standard sooting laminar diffusion flame, resulting in reasonable particle size distributions. For one location in the flame the comparison to literature is possible. Our particle sizes are smaller than those that were determined by TEM measurements in this defined standard position (center line at $\mathrm{HAB}=42 \mathrm{~mm}$ ). This deviation might be due to an insufficiently modelled surface vaporization at our used laser fluences in combination with a too low temporal resolution close to the signal peak. On the other hand, the limited spatial resolution of the intrusive TEM sampling process can lead to a superposition of sizes attributed to slightly different location for our imaging resolution. Future work shall focus on lower laser fluence for LII excitation and a detailed study about the required number of discrete time-shifted camera gates for receiving a certain precision of the results, pointing towards future application in technical flames, as well as implementation of a sub-model for realistic aggregation. However, the now available full 2D primary particle size field provides important validation information in addition to accurate temperature data (this work) and soot concentrations (from literature) for soot modelers, even if the accuracy of the approach can be optimized in future. In addition, the data will serve as reference to others applying new experimental set-ups to this measurement object requiring high spatial resolution. Further optimization, i.e. higher robustness of the fitting procedure is expected by use of $2 \mathrm{D}$ auto-compensating LII, requiring two spectrally filtering CCD cameras to determine absolute LII intensity. Following our suggested approach, shifting both CCD gates then allows determining the 2D temperature decay map, leading to a more robust data analysis. However, this is by far beyond the scope of this paper. 


\section{Acknowledgements}

The authors acknowledge the support of a Helmholtz/NRC collaborative partnership which made this research possible.

\section{References}

[1] Environmental Protection Agency (EPA), Health effects assessment document for diesel engine exhaust. EPA/600/8-90/057F. May 2002.

[2] M.Z. Jacobson, Strong radiative heating due to the mixing state of black carbon in atmospheric aerosols, Nature 409, 695-697 (2001).

[3] D.S. Lee, D.W. Fahey, P.M. Forster, P.J. Newton, R.C.N. Wit, L.L. Lim, B. Owen, R. Sausen, Aviation and global climate change in the 21st century, Atm. Env. 43, 3520-3537 (2009).

[4] U. Burkhardt, B. Kärcher, Global radiative forcing from contrail cirrus, Nat. Clim. Change 1, 54-58 (2011).

[5] C. Azar, D.J.A. Johansson, Valuing the non- $\mathrm{CO}_{2}$ climate impacts of aviation, Clim. Change 111, 559-579 (2012).

[6] H. Geitlinger, T. Streibel, R. Suntz, H. Bockhorn, Two-dimensional imaging of soot volume fractions, particle number densities, and particle radii in laminar and turbulent diffusion flames, Proc. Combust. Inst. 27, 1613-1621 (1998).

[7] H. Geitlinger, T. Streibel, R. Suntz, H. Bockhorn, Two dimensional imaging of sizes and number densities of nanoscaled particles, Proc. 10th Int. Symposium on Applications of Laser Technologies to Fluid Mechanics, Lissabon, Portugal, (2000).

[8] O. Angrill, H. Geitlinger, T. Streibel, R. Suntz, H. Bockhorn, Influence of exhaust gas recirculation on soot formation in diffusion flames, Proc. Combust. Inst. 28, 2643-2649 (2000).

[9] H. Bladh, P. Bengtsson, J. Delhay, Y. Bouvier, E. Therssen, P. Desgroux, Experimental and theoretical comparison of spatially resolved laser-induced incandescence signals of soot in backward and right-angle configuration, Appl. Phys. B 83, 423-433 (2006).

[10] J.A. Pinson, D.L. Mitchell, R.J. Santoro, T.A. Litzinger, Quantitative, planar soot measurements in a D.I. diesel engine using laser-induced incandescence and light scattering, SAE Paper 932650 Warrendale, Pa., 1993.

[11] K. Tian, F. Liu, K.A. Thomson, D.R. Snelling, G.J. Smallwood, D. Wang, Distribution of the number of primary particles of soot aggregates in a nonpremixed laminar flame, Combust. Flame 138, 195-198 (2004).

[12] S. Will, S. Schraml, A. Leipertz, Two-dimensional soot-particle sizing by time-resolved laser-induced incandescence, Opt. Lett. 20, 2342-2344 (1995).

[13] J. Johnsson, Laser-Induced Incandescence for soot diagnostics: Theoretical investigation and experimental development, PhD Thesis, Division of Combustion Physics, Department of Physics, Lund University (2012). 
[14] S. Will, S. Schraml, K. Bader, A. Leipertz, Performance characteristics of soot primary particle size measurements by time-resolved laser-induced incandescence, Appl. Opt. 37, 5647-5658 (1998).

[15] S. Will, S. Schraml, A. Leipertz, Comprehensive two-dimensional soot diagnostics based on LII, Proc. Combust. Inst. 26, 2277-2284 (1996).

[16] R.A. Dobbins, R.J. Santoro, H.G. Semerjian, Analysis of light scattering from soot using optical cross sections for aggregates, Proc. Combust. Inst. 23, 1525-1532 (1990).

[17] K.A. Thomson, K.P. Geigle, M. Köhler, G.J. Smallwood, D.R. Snelling,Optical properties of pulse laser heated soot, Appl. Phys. B 104 , 307-319 (2011).

[18] D.R. Snelling, K. A. Thomson, G. J. Smallwood, Ö. L. Gülder, Two-dimensional imaging of soot volume fraction in laminar diffusion flames, Appl. Opt. 38, 2478-2485 (1999).

[19] C. Schulz, B.F. Kock, M. Hofmann, H. Michelsen, S. Will, B. Bougie, R. Suntz, G. Smallwood, Laser-induced incandescence: recent trends and current questions, Appl. Phys. B 83, 333-354 (2006).

[20] M. Charwath, R. Suntz, H. Bockhorn, Influence of the temporal response of the detection system on time-resolved laser-induced incandescence signal evolutions, Appl. Phys. B 83, 435-442 (2006).

[21] S. Schraml, S. Dankers, K. Bader, S. Will, A. Leipertz, Soot Temperature Measurements and Implications on Time-Resolved Laser-Induced Incandescence (TIRE-LII), Combust. Flame 120, 439-450 (2000).

[22] Sample III Research Project EASA.2010.FC10-SC.02, http://easa.europa.eu/safety-and-research/research-projects/docs/environment/SAMPLE\%20III-SC02 \%20Final\%20report.pdf

[23] R. Hadef, K.P. Geigle, W. Meier, M. Aigner, Soot characterization with laser-induced incandescence applied to a laminar premixed ethylene-air flame, Int. J. Thermal Sci. 49, 1457-1467 (2010).

[24] L.E. Fried, W.M. Howard, Explicit Gibbs free energy equation of state applied to the carbon phase diagram, Phys. Rev. B 61, 8734-8743 (2000).

[25] H.A. Michelsen, Understanding and predicting the temporal response of laser-induced incandescence from carbonaceous particles, J. Chem. Phys.118, 7012-7045 (2003).

[26] S.S. Krishnan, K.-C. Lin, G.M. Faeth, Optical properties in the visible of overfire soot in large buoyant turbulent diffusion flames, J. Heat Transfer 122, 517-524 (2000).

[27] D.R. Snelling, F. Liu, G.J. Smallwood, Ö. L Gülder, Determination of the soot absorption function and thermal accommodation coefficient using low-fluence LII in a laminar coflow ethylene diffusion flame, Combust. Flame 136, 180-190 (2004).

[28] A.V. Filippov, D.E. Rosner, Energy Transfer between an Aerosol Particle and Gas at High Temperature Ratios in the Knudsen Transition Regime, Int. J. Heat and Mass Transfer 43, 127-138 (2000).

[29] J. Hager, D. Glatzer, H. Walther, H. Kuze, M. Fink, Rotationally excited NO molecules incident on a graphite surface: molecular rotation and translation after scattering, Surf. Sci. 374, 181-190 
(1997).

[30] L.A. Melton, Soot Diagnostics Based on Laser Heating, Appl. Opt. 23, 2201-2208 (1984).

[31] M. Kholghy, M. Saffaripour, C Yip, M.J. Thomson, The evolution of soot morphology in an atmospheric laminar coflow diffusion flame of a surrogate for Jet A-1, Combust. Flame, accepted

[32] J. Johnsson, H. Bladh, P.-E. Bengtsson, On the influence of bimodal size distributions in particle sizing using laser-induced incandescence, Appl. Phys B 99, 817-823 (2010).

[33] W.C. Hinds, Aerosol Technology, Wiley, New York, 1982.

[34] R.L. Vander Wal, K. Jensen, Laser-induced incandescence: Excitation intensity, Appl. Opt. 37, 1607-1616 (1998).

[35] F. Liu, H. Guo, G.J. Smallwood, Ö.L. Gülder, Effects of gas and soot radiation on soot formation in a coflow laminar ethylene diffusion flame, J. Quant. Spectrosc. Rad. Transf. 73, 409-421 (2002).

[36] M.D. Smooke, C.S. McEnally, L.D. Pfefferle, R.J. Hall, M.B. Colket, Computational and experimental study of soot formation in a coflow, laminar diffusion flame, Combust. Flame 117, 117-139 (1999).

[37] S. Trottier, H. Guo, G.J. Smallwood, M.R. Johnson, Measurement and modeling of the sooting propensity of binary fuel mixtures, Proc. Combust. Inst. 31, 611-619 (2007).

[38] Ö.L. Gülder, D.R. Snelling, R.A. Sawchuk, Influence of hydrogen addition to fuel on temperature field and soot formation in diffusion flames, Proc. Combust. Inst. 26, 2351-2358 (1996).

[39] D.R. Snelling, K.A. Thomson, G.J. Smallwood, Ö.L. Gülder, E.J. Weckman, R.A. Fraser, Spectrally resolved measurement of flame radiation to determine soot temperature and concentration, AIAA Journal 40, 1789-1795 (2002).

[40] D.R. Snelling, R.A. Sawchuk, G.J. Smallwood, T. Parameswaran, An improved CARS spectrometer for single-shot measurements in turbulent combustion, Rev. Sci. Instrum. 63, 5556-5564 (1992).

[41] D.R. Snelling, R.A. Sawchuk, T. Parameswaran, Noise in single-shot broadband coherent anti-Stokes Raman spectroscopy that employs a modeless dye laser, Appl. Opt. 33, 8295-8301 (1994). [42] P.-E. Bengtsson, M. Aldén, S. Kroll, D. Nilsson, Vibrational CARS Thermometry in Sooty Flames: Quantitative Evaluation of $C_{2}$ Absorption Interference, Combust. Flame 82, 199-210 (1990).

[43] M.S. Tsurikov, K.P. Geigle, V. Krüger, Y. Schneider-Kühnle, W. Stricker, R. Lückerath, R. Hadef, M. Aigner, Laser-based investigation of soot formation in laminar premixed flames at atmospheric and elevated pressures, Combust. Sci. Technol. 177, 1835-1862 (2005).

[44] F. Beyrau, A. Datta, T. Seeger, A. Leipertz, Dual-pump CARS for the simultaneous detection of $\mathrm{N}_{2}, \mathrm{O}_{2}$ and $\mathrm{CO}$ in $\mathrm{CH}_{4}$ flames, J. Raman Spectrosc.33, 919-924 (2002).

[45] W.S. Cleveland, S.J. Devlin, Locally weighted regression: an approach to regression analysis by local fitting, J. Am. Stat. Assoc. 83, 596-610 (1988).

[46] U. Vandsburger, I. Kennedy, I. Glassman, Sooting counterflow diffusion flames with varying oxygen index, Combust. Sci. Technol. 39, 263-285 (1984). 
[47] K.M. Leung, R.P. Lindstedt, W.P. Jones, A simplified reaction mechanism for soot formation in nonpremixed flames, Combust. Flame 87, 289-305 (1991).

[48] J.H. Kent, H. Gg Wagner, Temperature and fuel effects in sooting diffusion flames, Proc. Combust. Inst. 20, 1007-1015, (1984).

[49] L.R. Boedeker, G.M. Dobbs, CARS temperature measurements in sooting laminar diffusion flames, Combust. Sci. Technol. 46, 301 - 323 (1986).

[50] G.H. Markstein, Relationship between soot point and radiant emission from buoyant turbulent and laminar diffusion flames. Proc. Combust. Inst. 20, 1055-1061 (1984).

[51] R.J. Santoro, H.G. Semerjian, Soot formation in diffusion flames: flow rate, fuel species and temperature effects, Proc. Combust. Inst. 20, 997-1006 (1984).

[52] K.J. Daun, B.J. Stagg, F. Liu, G.J. Smallwood, D.R. Snelling, Determining aerosol particle size distributions using time-resolved laser-induced incandescence, Appl. Phys. B 87, 363-372 (2007).

[53] R.A. Dobbins, C.M. Megaridis, Morphology of flame-generated soot as determined by thermophoretic sampling, Langmuir 3, 254-259 (1987).

[54] A.D Anna, A. Rolando, C. Allouis, P. Minutolo, A. D’Alessio, Nano-organic carbon and soot particle measurements in a laminar ethylene diffusion flame, Proc. Combust. Inst. 30, 1449-1456 (2005).

[55] D.R. Snelling, K.A. Thomson, F. Liu, G.J. Smallwood, Comparison of LII derived soot temperature measurements with LII model predictions for soot in a laminar diffusion flame, Appl. Phys. B 96, 657-669 (2009).

[56] J. Johnsson, H. Bladh, N.-E. Olofsson, P.-E. Bengtsson, Influence of soot aggregate structure on particle sizing using laser-induced incandescence: Importance of bridging between primary particles, Appl. Phys. B (2013) doi 10.1007/s00340-013-5355-z.

[57] R. Stirn, T. Gonzalez Baquet, S. R. Kanjarkar, W. Meier, K.P. Geigle, H.-H. Grotheer, C. Wahl, M. Aigner, Comparison of particle size measurements with laser-induced incandescence, mass spectroscopy and scanning mobility particle sizing in a laminar premixed ethylene/air flame, Combust. Sci. Technol. 181, 329-349 (2009).

[58] B.F. Kock, B. Tribalet, C. Schulz, P. Roth, Two-color time-resolved LII applied to soot particle sizing in the cylinder of a Diesel engine, Combust. Flame 147, 79-92 (2006).

[59] H. Bladh, J. Johnsson, J. Rissler, H. Abdulhamid, N.-E. Olofsson, M. Sanati, J. Pagels, P.-E. Bengtsson, Influence of soot particle aggregation on time-resolved laser-induced incandescence signals, Appl. Phys. B 104, 331-341 (2011).

[60] H.A. Michelsen, F. Liu, B.F. Kock, H. Bladh, A. Boiarciuc, M. Charwath, T. Dreier, R. Hadef, M. Hofmann, J. Reimann, S. Will, P. Bengtsson, H. Bockhorn, F. Foucher, K.P. Geigle, C. Mounaim-Rousselle, C. Schulz, R. Stirn, B. Tribalet, R. Suntz, Modeling laser-induced incandescence of soot: a summary and comparison of LII models, Applied Physics B 87, 503-521 (2007).

[61] J. Hult, A. Omrane, J. Nygren, C. F. Kaminski, B. Axelsson, R. Collin, P.-E. Bengtsson, M. Aldén, Quantitative three-dimensional imaging of soot volume fraction in turbulent non-premixed 
flames, Experiments in Fluids 33, 265-269 (2002).

[62] H. Bladh, J. Johnsson, N.-E. Olofsson, A. Bohlin, P.-E. Bengtsson, Optical soot characterization using two-color laser-induced incandescence (2C-LII) in the soot growth region of a premixed flat flame, Proc. Combust. Inst. 33, 641-648 (2011). 


\section{Figure captions}

Fig. 1: Calculated energy rates $\left(F_{0}=0.4 \mathrm{~J} / \mathrm{cm}^{2}, \lambda_{\text {las }}=1064 \mathrm{~nm}, T_{g}=1800 \mathrm{~K}, D_{0}=20 \mathrm{~nm}, \lambda_{\text {det }}=450 \mathrm{~nm}\right)$.

Fig. 2: Model results for the signal decay from different sized particles illuminated by a $0.4 \mathrm{~J} / \mathrm{cm}^{2}$ laser pulse at $1064 \mathrm{~nm}$. Detection is at $450 \mathrm{~nm}$, ambient temperature for this example is $1800 \mathrm{~K}$.

Fig. 3. Comparison of model results (solid curve) with measured LII temporal profiles [25]. Indicated values are used fluences in $\mathrm{J} / \mathrm{cm}^{2}$.

Fig. 4: Photograph of the sooting flame.

Fig. 5: Experimental set-up of the LII technique (left) and principle of our measurements (right) in comparison to $[12,14,15]$.

Fig. 6: Soot luminosity image of the flame (left) and 2D-LII signal (center). The right plot represents radial profiles of the LII signal intensity (subsenquently soot volume fraction).

Fig. 7: CARS temperature radial profiles (left) covering the region of interest for our TiRe LII analysis. For $H A B=50 \mathrm{~mm}$ a smoothed profile is shown indicating the step size required for particle sizing, the plot on the right shows a $2 \mathrm{D}$ interpolation.

Fig. 8: $2 \mathrm{D} \mathrm{LIl} \mathrm{at} \mathrm{different} \mathrm{instants} \mathrm{of} \mathrm{decay.} \mathrm{The} \mathrm{strongest} \mathrm{signal} \mathrm{from} \mathrm{the} \mathrm{largest} \mathrm{primary} \mathrm{particles} \mathrm{lasts}$ approximately $2.5 \mu$ s out of which the first $1.5 \mu$ s could be used for further analysis.

Fig. 9.a: Maximum likelihood estimator for a given signal and different calculated signals as a function of $C M D$ and $\sigma_{\mathrm{g}}(r=0 \mathrm{~mm}, H A B=42 \mathrm{~mm})$. Fig. 9.b: Temporal LII signal decays, measured $(r=0 \mathrm{~mm}, H A B=42 \mathrm{~mm})$ and calculated $\left(C M D=16.5 \mathrm{~nm}, \sigma_{\mathrm{g}}=0.37\right)$. Fig. 9.c: Particle size distribution calculated for $C M D=16.5 \mathrm{~nm}$ and $\sigma_{g}=0.37$.

Fig. 10: 2D soot particle diameter measurements, for better visualization overlayed with LII image (left), and particle diameter profiles for some axial locations (right). The circle sizes visualize particle diameters; a reference particle spere of $30 \mathrm{~nm}$ is included as legend.

Fig. 11: correlation of profiles at exemplary $H A B=30 \mathrm{~mm}$ for soot volume fraction (x), primary particle size ( $\mathbf{m})$ and temperature $(\triangleleft)$.The width of the size distribution (right plot) follows the trend of particle size. 


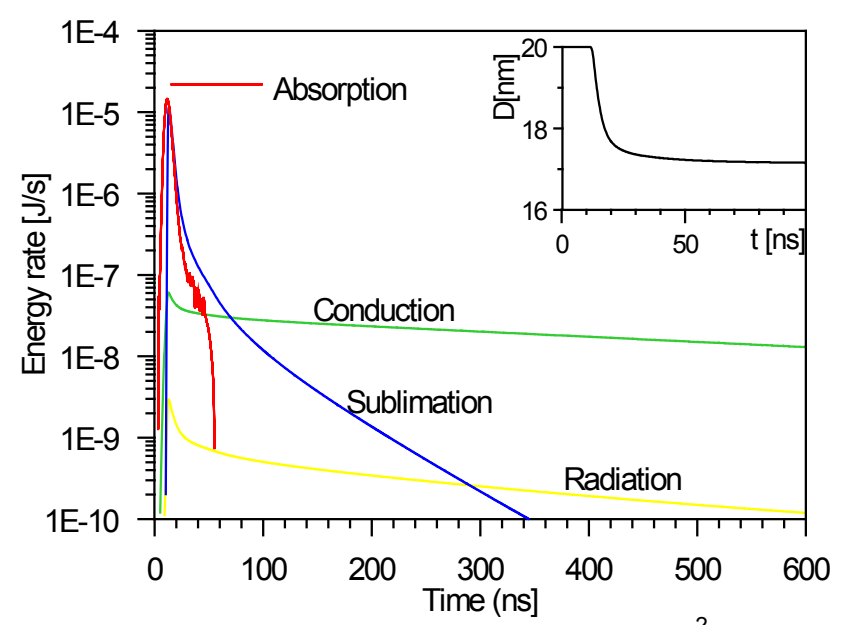

Fig. 1: Calculated energy rates $\left(F_{0}=0.4 \mathrm{~J} / \mathrm{cm}^{2}, \lambda_{\text {las }}=1064 \mathrm{~nm}, T_{g}=1800 \mathrm{~K}, D_{0}=20 \mathrm{~nm}, \lambda_{\text {det }}=450 \mathrm{~nm}\right)$.

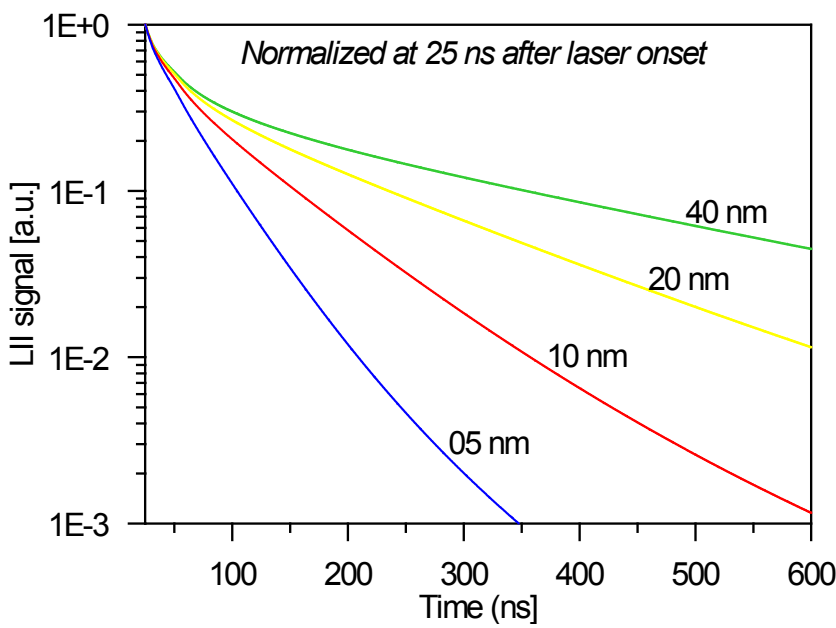

Fig. 2: Model results for the signal decay from different sized particles illuminated by a $0.4 \mathrm{~J} / \mathrm{cm}^{2}$ laser pulse at $1064 \mathrm{~nm}$. Detection is at $450 \mathrm{~nm}$, ambient temperature for this example is $1800 \mathrm{~K}$. 


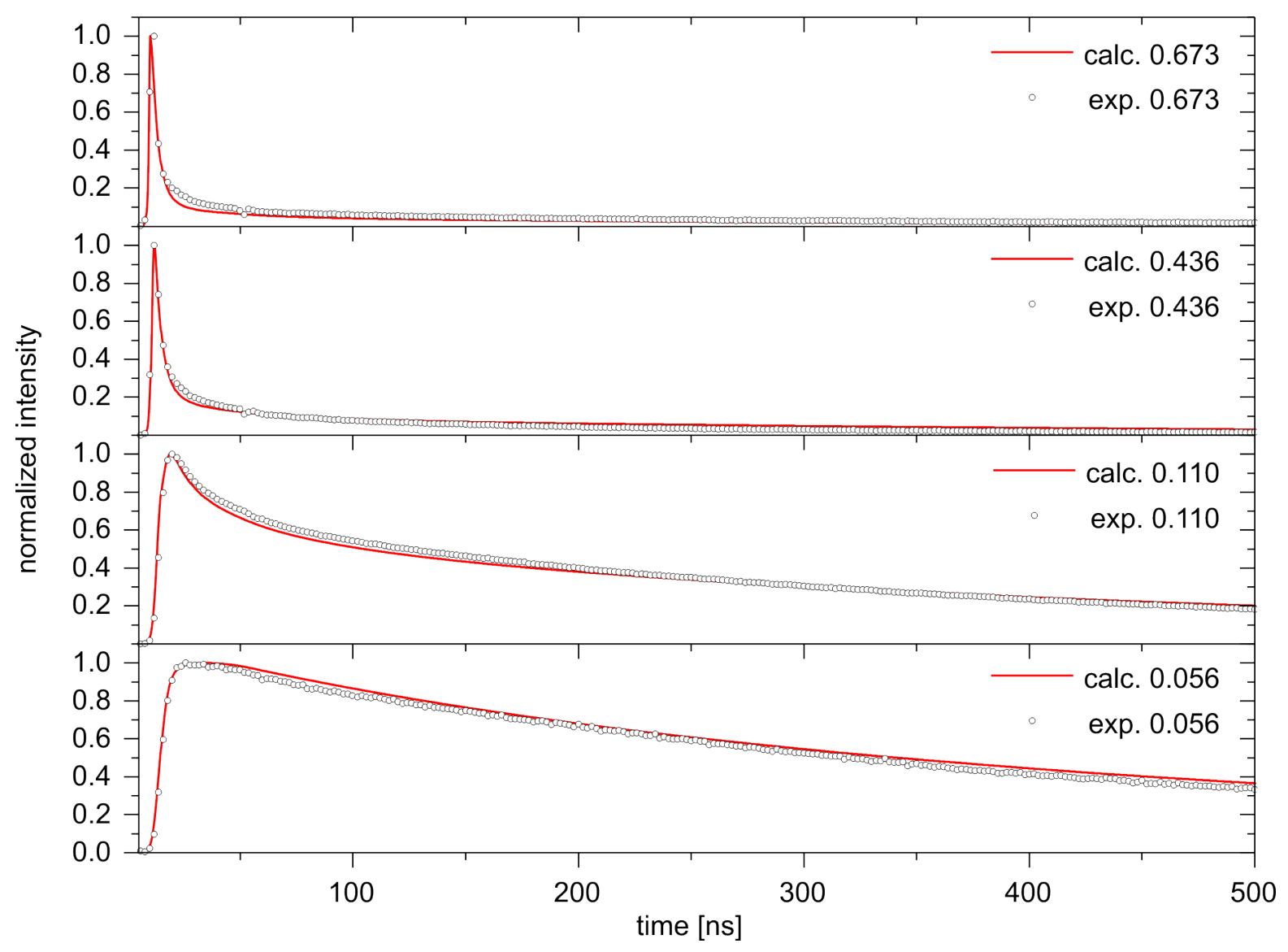

Fig. 3. Comparison of model results (solid curve) with measured LII temporal profiles [25]. Indicated values are used fluences in $\mathrm{J} / \mathrm{cm}^{2}$.

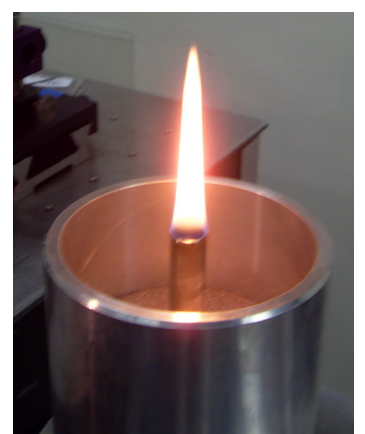

Fig. 4: Photograph of the sooting flame. 

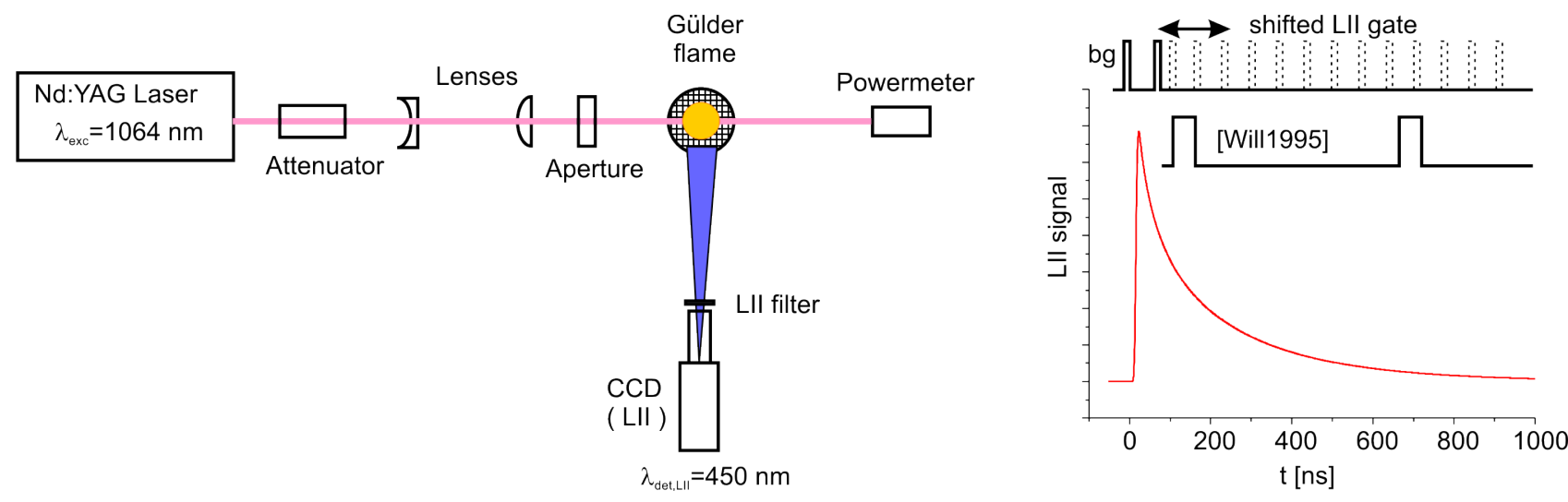

Fig. 5: Experimental set-up of the LII technique (left) and principle of our measurements (right) in comparison to $[12,14,15]$.
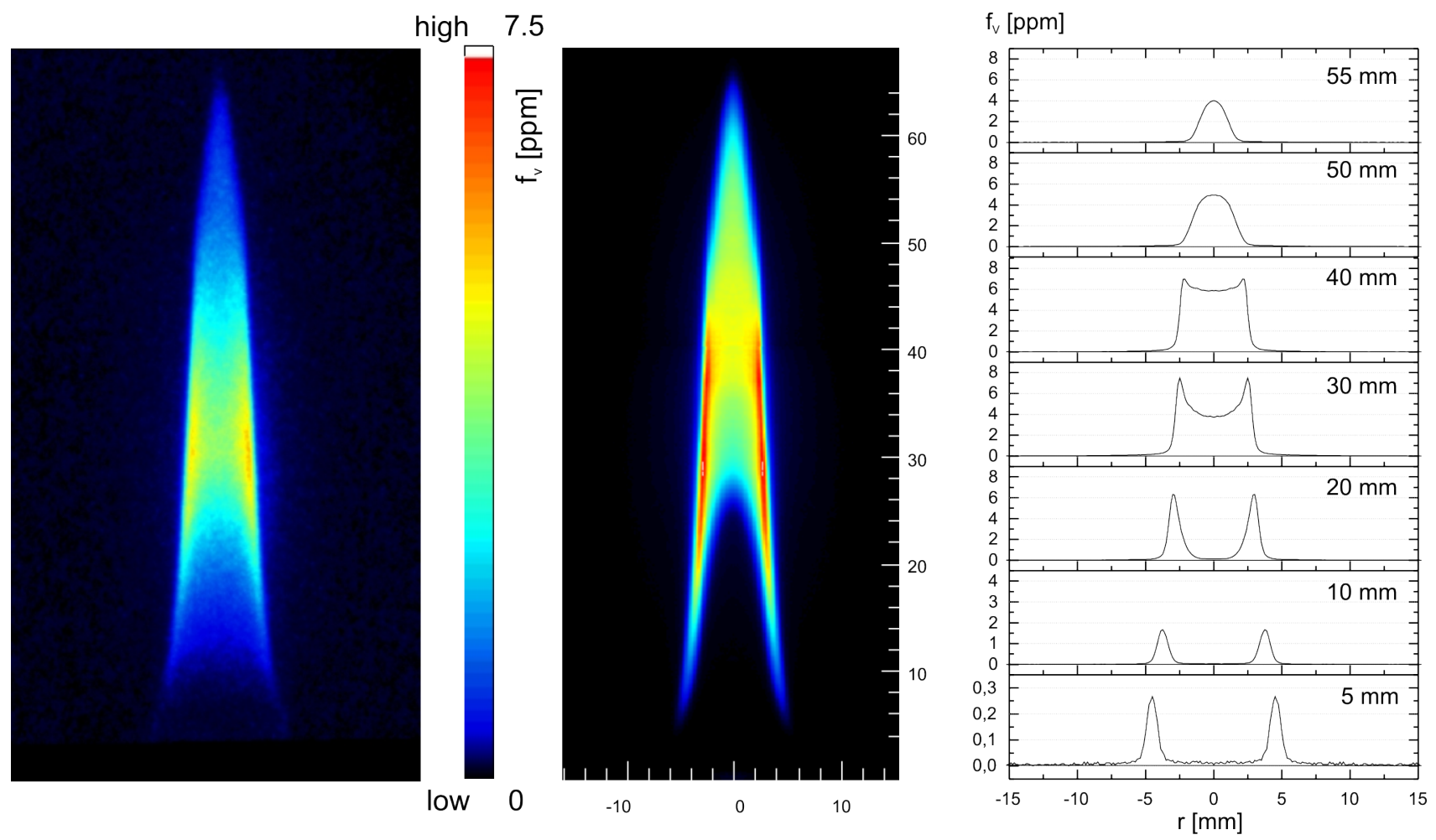

Fig. 6: Soot luminosity image of the flame (left) and 2D-LII signal (center). The right plot represents radial profiles of the LII signal intensity (subsenquently soot volume fraction). 

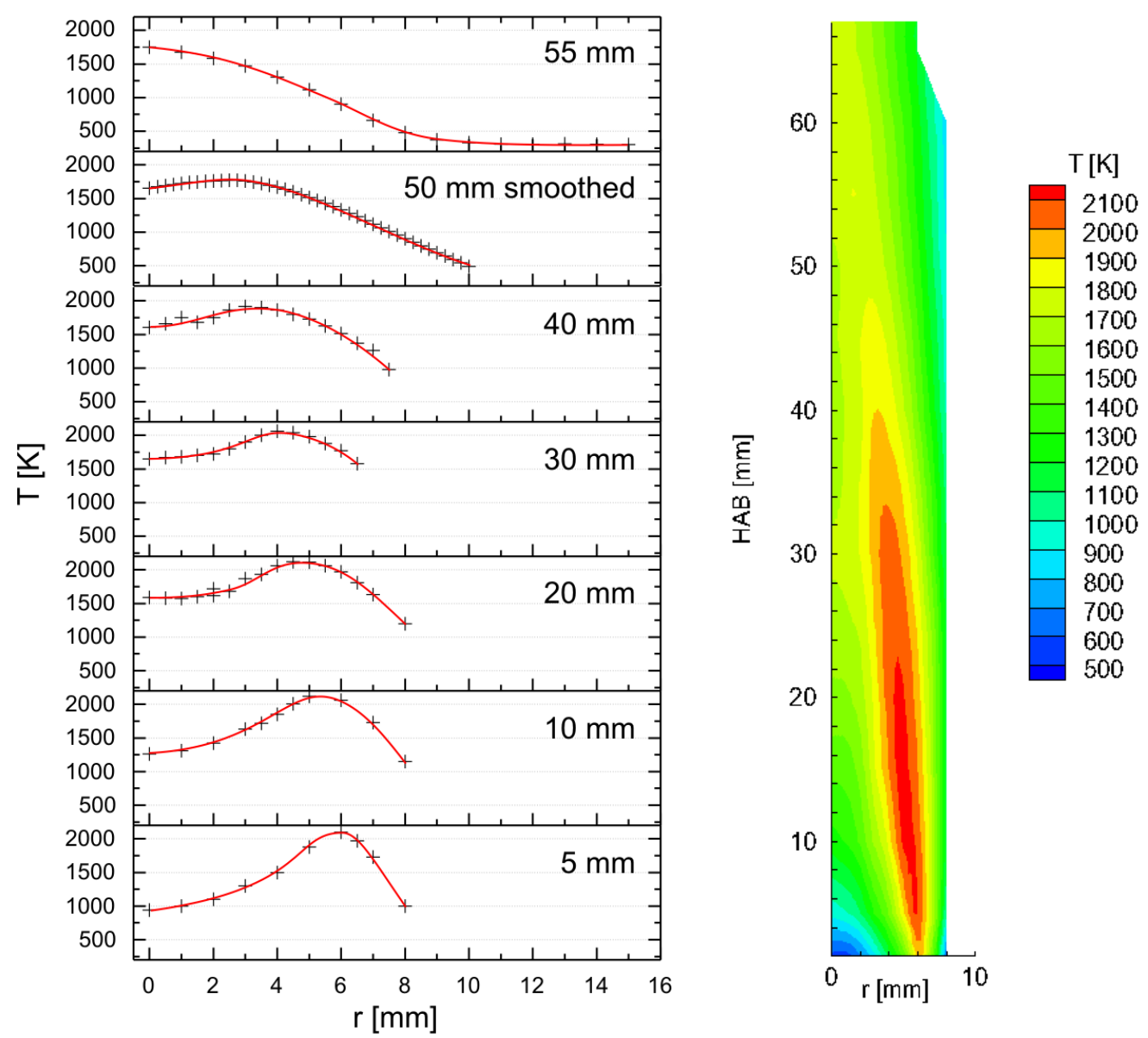

Fig. 7: CARS temperature radial profiles (left) covering the region of interest for our TiRe LII analysis. For $H A B=50 \mathrm{~mm}$ a smoothed profile is shown indicating the step size required for particle sizing, the plot on the right shows a 2D interpolation.

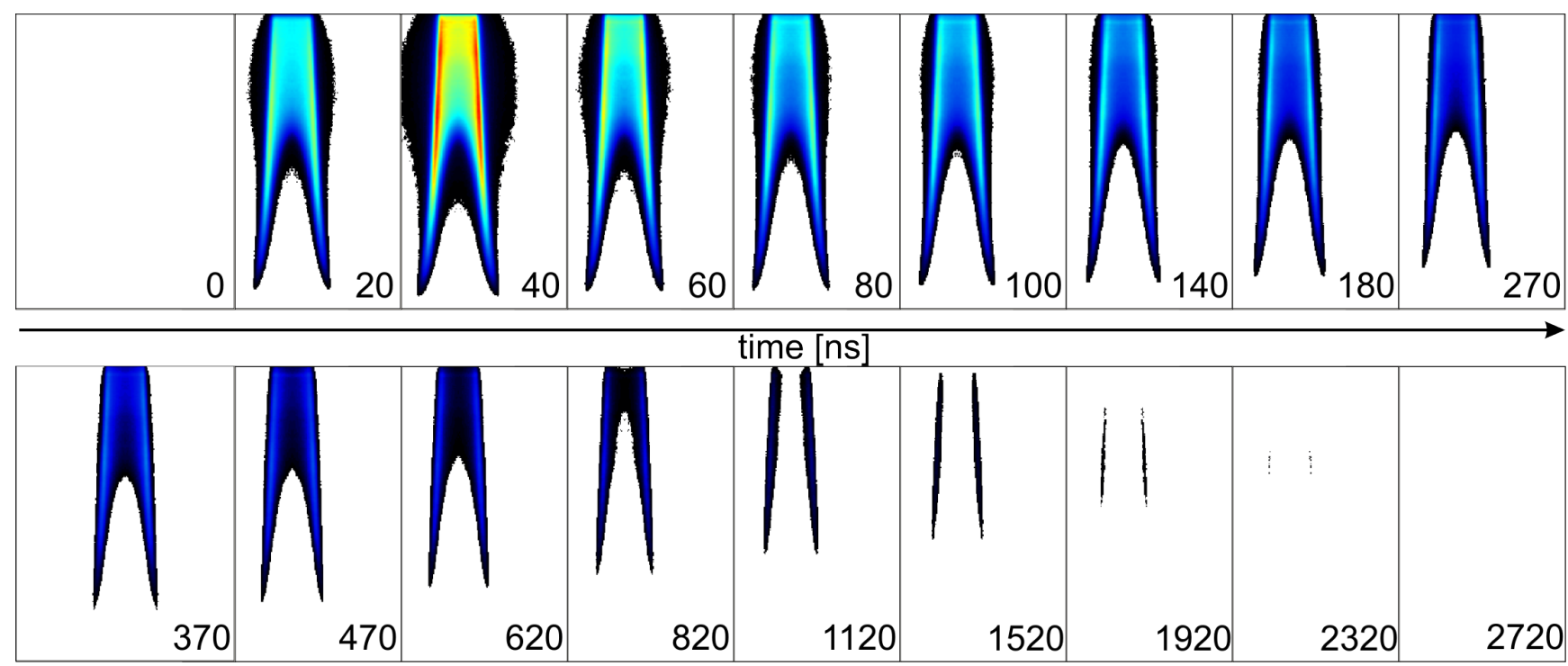

Fig. 8: $2 \mathrm{D}$ LII at different instants of decay. The strongest signal from the largest primary particles lasts approximately $2.5 \mu \mathrm{s}$ out of which the first $1.5 \mu \mathrm{s}$ could be used for further analysis. 

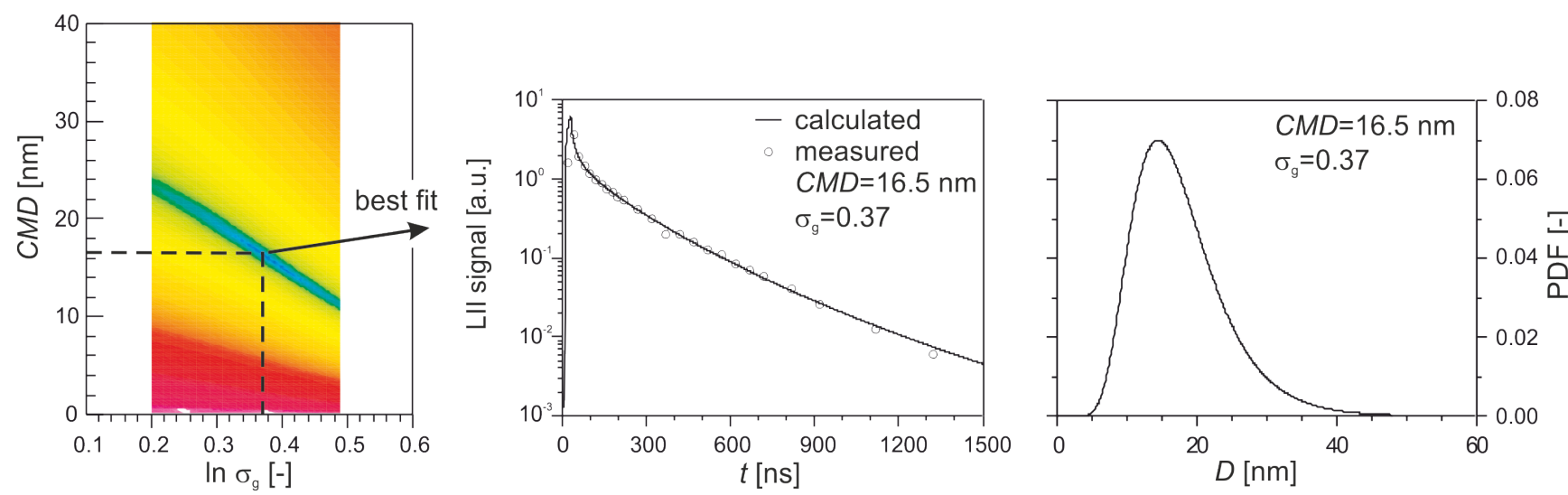

Fig. 9.a: Maximum likelihood estimator for a given signal and different calculated signals as a function of $C M D$ and $\sigma_{g}(r=0 \mathrm{~mm}, H A B=42 \mathrm{~mm})$. Fig. 9.b: Temporal Lll signal decays, measured $(r=0 \mathrm{~mm}, H A B=42 \mathrm{~mm})$ and calculated $\left(C M D=16.5 \mathrm{~nm}, \sigma_{g}=0.37\right)$. Fig. 9.c: Particle size distribution calculated for $C M D=16.5 \mathrm{~nm}$ and $\sigma_{g}=0.37$.
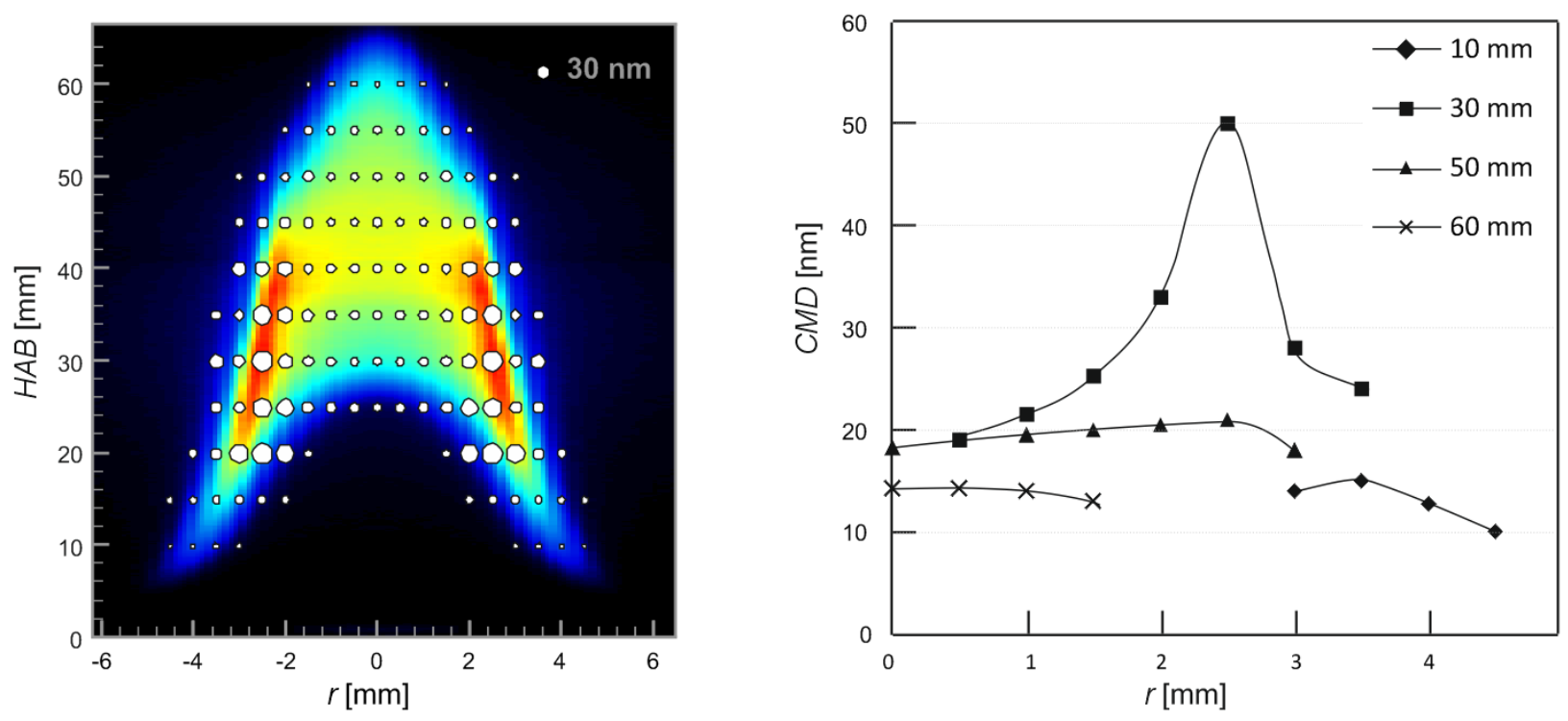

Fig. 10: 2D soot particle diameter measurements, for better visualization overlayed with LII image (left), and particle diameter profiles for some axial locations (right). The circle sizes visualize particle diameters; a reference particle spere of $30 \mathrm{~nm}$ is included as legend. 

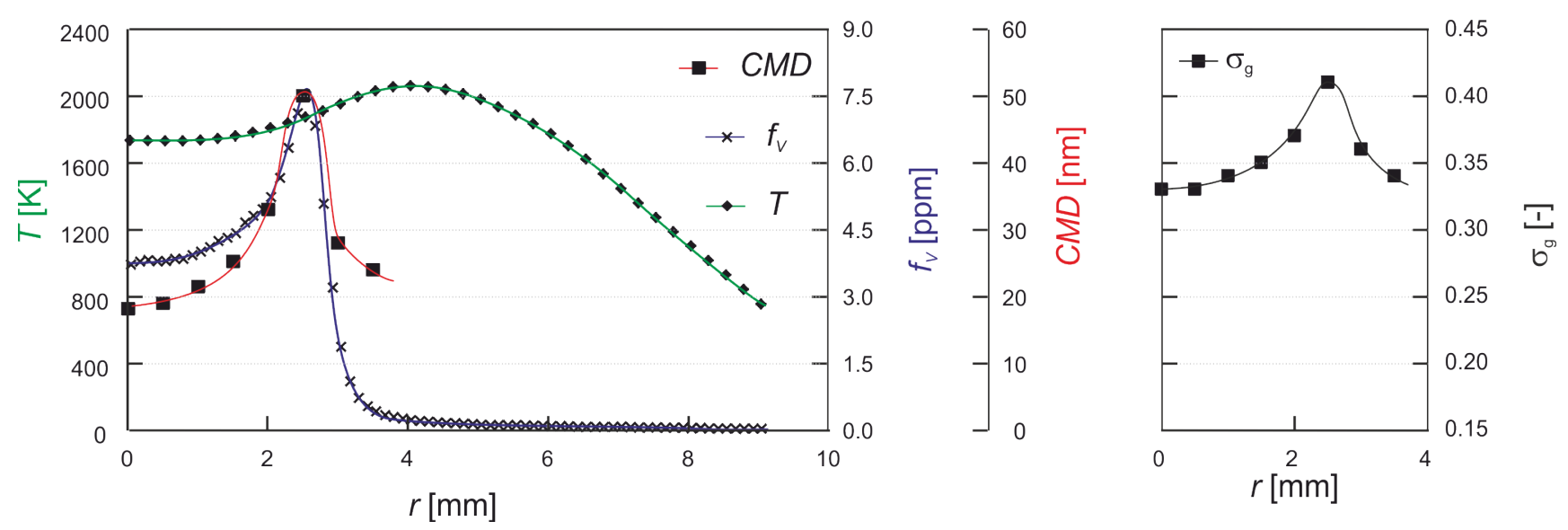

Fig. 11: Correlation of profiles at exemplary $H A B=30 \mathrm{~mm}$ for soot volume fraction (x), primary particle size ( - ) and temperature $(\bullet)$. The width of the size distribution (right plot) follows the trend of particle size. 